\title{
Correlation study between DHFR enzyme and some biochemical parameters in diabetic type II patients
}

\author{
Shayma`a J. Ahmed ${ }^{1}$, Manal K Rasheed ${ }^{2} \&$ Kifah Hamdan Abdul Ghafour ${ }^{3}$ \\ ${ }^{1}$ Anatomy Depart.- College of Medicine-Baghdad University. \\ ${ }^{2}$ Biochemical Depart.- College of Medicine-Baghdad University. \\ ${ }^{3}$ Pathology Depart.- College of Medicine-Baghdad University.
}

\begin{abstract}
Dihydrofolatereductase (DHFR)enzyme, Fasting Blood Sugar and some biochemical parameters were determined in (88) sample, (20) the control group which 10 males \& 10 females) \& (68) the patients(24 male \&44 female) how were out-patient clinic in Baghdad hospital and had diabetic type II.

There are significant differences in mean value between patient (male, female) group and control group in FBG, urea, $T G$ chol. $H D L$, creatinine, $N a \& K$, while there is significant difference in mean value of ALP between patient group \& control group and mean value of chloride between patient group \& control group and there are highly significant differences in mean value between patient group and control group in ALT \& AST.

There was correlation between the DHFR and FBG,ALP, chl. TG in male patients and positive non significant between DHFR and ALT, AST. DHFR levels were negative significant correlated with urea $H D L, C r e a t . N a$ but non- significant with $K$ but the correlation was in female patients between the DHFR and FBG, ALP, Chl., TG, AST and positive non significant between DHFR and ALT. DHFR levels were negative significant correlated with Na but non- significant with urea,HDL,Creat. and $K$.
\end{abstract}

Key words: Dihydrofolatereductase (DHFR)enzyme, Fasting Blood Sugar and biochemical tests.

\section{Introduction:}

Dihydrofolatereductase (DHFR; 5,6,7,8-tetrahydro- folate : NADP+ oxidoreductase) (a $24 \mathrm{kDa}$ protein) catalyzes the NADPH-dependent reduction of dihydrofolate $\left(\mathrm{H}_{2}\right.$ folate $)$ or folic acid to tetrahydrofolate $\left(\mathrm{H}_{4}\right.$ folate $)$ and is considered to be a key enzyme in folate metabolism[1]. $\mathrm{H}_{2}$ folate is the product of thymidylate synthetase and must be recycled to $\mathrm{H}_{4}$ folate in order to be incorporated into tetrahydrofolate metabolic pool. After reduction of $\mathrm{H}_{2}$ folate, $\mathrm{H}_{4}$ folate receives one carbon unit and acts as a one-carbon donor in the biosynthesis of purines and pyrimidines and in the interconversion of amino acids [2]. Tetrahydrofolate acts as a methyl group shuttle re-quired for the de novo synthesis of purines, thymidylic acid, and certain amino acids[3].

As tetrahydrofolate, the product of this reaction is the active form of folate in humans, inhibition of DHFR can cause functional folate deficiency. Folate is needed by rapidly dividing cells to make thymine, this effect may be therapeutic. For example, methotrexate is used in cancer chemotherapy because it can prevent neoplastic cells from dividing[4].

So, DHFR has become very important nowadays in making anti-cancer drugs due to its inhibition by methotrexate . Its binding to methotrexate depends on its con-formation, so it is very necessary that it should be pre-sent in its correctly folded form[1].

A significant contemporary question in enzymology involves the role of protein dynamics and hydrogen tunneling in enhancing enzyme catalyzed reactions. Here, we report a correlation between the donor-acceptor distance (DAD) distribution and intrinsic kinetic isotope effects (KIEs) for the dihydrofolate reductase (DHFR) catalyzed reaction $[5,6]$.

In this research we studied the correlation between the DHFR and some biochemical parameters in( females $\&$ males) patients who had diabetic type II.

\section{Patients and methods:}

- Patients: In this study (88) blood samples(the serum) were collected and divided in two groups:

(20) the control group which(10 males \& 10 females) \& (68) the patients(diabetic type II ) group who they were received in the out-patient clinic in Baghdad hospital during the period from October-December 2011, they were (24 males \& 44 females).

- Materials :NAPDH, was from (Serva). $\mathrm{KH} 2 \mathrm{PO} 4, \mathrm{Na} 2 \mathrm{HCO} 3, \mathrm{NaCl} 2$ were from (BDH), Dihydrofolate (Sigma) .

-Dihydroflate reductase enzyme assay:

The DHFR enzyme activity was assayed essentially according to the method of Haurani et. al . [7] with some modification. The assay for DHFR was performed at $37^{\circ} \mathrm{C}$ by spectrophotometer method, which utilizes the decrease in absorbency at $340 \mathrm{~nm}$ when NADPH and dihydrofolate are converted to NADP and tetrahydrofolates 
Enzyme activity is expressed as nano mol dihydro-folate reduced/mg protein .The reaction mixture contains $2 \mathrm{ml}$ (NADHP) $2 \mathrm{~mm} .0 .6 \mathrm{ml}$ of dihydrofolate and $50 \mathrm{ml}$ of enzyme suspension and read at every minute for $3 \mathrm{~min}$ [8].

A blood sample was collected after an overnight fast $\geq 8 \mathrm{~h}$. Blood glucose level was measured with enzymatic oxidation[9], Serum total cholesterol, Triglyceride ,High density lipid were measured ezymatically using a commercially available reagent mixture supplied by biomMerieux Sa-France[10], and creatinine was analyzed by the modified kinetic Jaffe reaction method [11]. Urea was measured by enzymatic method using a kit supplied by biomMerieux Sa-France [12].

Serum level of GOT(AST) and GOT (ALT) concentration were assayed based on dinitrophyenyl hydrazone a coupling calorimetric method ( by Randox-United Kingdom) using this technique .Serum level of ALP was determined by calorimetric method using phosphatase alkaline -kite provided by Biomerieux-France. The total bilirubin in serum of control and patients were measured by adding caffeine reagent as accelerator followed by the addition of diazotized sulfanilic acid [13]. The sodium ,potassium and chloride were determined by Atomic absorption spectrophotometer.

\section{- Statistical analysis:}

Statistical analysis of the results was done by using Excel software version 2007 to find the correlation between DHFR and other biochemical parameters in patients. Data are presented as mean \pm S.D. Differences between two groups were analyzed by the unpaired Student's t-test, A P value of $<0.05$ was considered statistically significant

\section{Results:}

Table (1) and figure(1) shown the mean $+\square$ SD of all biochemical parameters that involve in this study in patients (females\& males) and control.

Table (2) show depicts the correlation between the DHFR and other biochemical parameters in male patients .

Table (3) show depicts the correlation between the DHFR and other biochemical parameters in female patients .

Table 1: show the values of all parameters involved in the study in Patients(male ,female) and controls as (mean $\pm \mathrm{SD}$ ) grouped

\begin{tabular}{|c|c|c|c|}
\hline Parameters & Normal & Male/Patients & Female/Patients \\
\hline DHFR & $17.66(\mathrm{M})^{*} / 21.2(\mathrm{~F})^{*}$ & $28.20 \mp 20.68$ & $28.69 \mp 19.4$ \\
\hline Fasting blood sugar $\mathrm{mg} / \mathrm{dl}$ & $92 \mp 10.32 *$ & $236.61 \mp 42.46$ & $216.21 \mp 59.62$ \\
\hline $\begin{array}{l}\text { Serum alkaline } \\
\text { phosphatase(KA/L) }\end{array}$ & $86 \mp 51$ & $86.76 \mp 33.67$ & $91.40 \mp 25.20^{*}$ \\
\hline Blood urea $(\mathrm{mg} / \mathrm{dl})$ & $39 \mp 3.9^{*}$ & $51.66 \mp 42.46$ & $30.36 \mp 13.55^{*}$ \\
\hline Serum cholesterol $(\mathrm{mg} / \mathrm{dl})$ & $201.8 \mp 15.9 *$ & $163.75 \mp 28.65$ & $200.9 \mp 54.27 *$ \\
\hline Serum triglyceride $(\mathrm{mg} / \mathrm{dl})$ & $116.54 \mp 28.68^{*}$ & $127 \mp 52.75$ & $153 \mp 47.81 *$ \\
\hline Serum HDL (mg/dl) & $52.1 \mp 5.41 *$ & $42.65 \mp 14.69$ & $37.4 \mp 6.58^{*}$ \\
\hline Serum creatinine $(\mathrm{mg} / \mathrm{dl})$ & $0.75 \mp 0.15 *$ & $1.912 \mp 2.35^{*}$ & $0.84 \mp 0.746$ \\
\hline Serum sodium $(\mathrm{mmol} / \mathrm{l})$ & $144 \mp 5.8^{*}$ & $102.56 \mp 56.62 *$ & $138.33 \mp 2.58$ \\
\hline Serum potassium $(\mathrm{mmol} / \mathrm{l})$ & $4.6 \mp 0.7$ & $3.88 \mp 0.81^{*}$ & $4.1 \mp 0.42$ \\
\hline Serum chloride $(\mathrm{mmol} / \mathrm{l})$ & $99.67 \mp 3.1$ & $99.5 \mp 4.15$ & $102 \mp 2.34$ \\
\hline Serum total billirubin $(\mathrm{mg} / \mathrm{dl})$ & $0.58 \mp 0.22$ & $0.99 \mp 1.457$ & $0.72 \mp 0.48$ \\
\hline $\begin{array}{l}\text { Serum alanine glutamate } \\
\text { transferase(ALT)(IU/L) }\end{array}$ & $8.9 \mp 0.59$ & $24.75 \mp 15.38 *$ & $19.13 \mp 9.71^{*}$ \\
\hline $\begin{array}{l}\text { Serum Aspartate glutamate } \\
\text { transferase(AST) (IU/L) }\end{array}$ & $10.86 \mp 0.68^{*}$ & $32.16 \mp 27.02$ & $\mp 7.7^{*}$ \\
\hline
\end{tabular}

*Significant $\mathrm{p}<0.05$ 


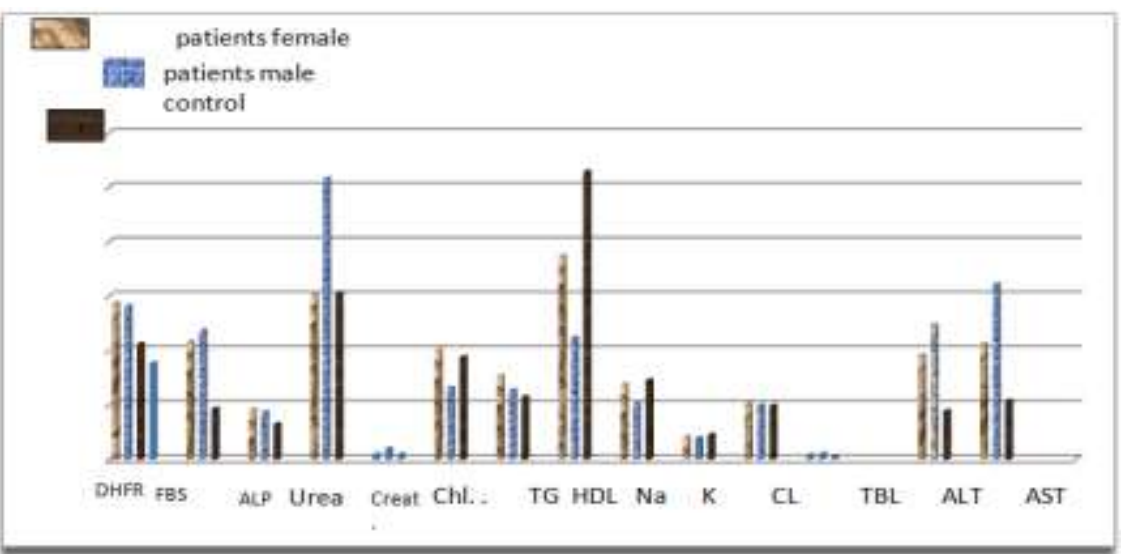

FBSX10

TGX10

CLx10,

ALPX1

0

$\operatorname{Nax} 10$,

Figure 1: mean value of main biochemical parameters in patients (male, female)and control .

Table 2: correlation between DHFR and other biochemical parameters in male patients :

\begin{tabular}{|c|c|c|}
\hline correlation & r-value & p-value \\
\hline DHFR and FBS & 0.14 & $<0.05$ \\
\hline DHFR and ALP & 0.18 & $<0.05$ \\
\hline DHFR and urea & -0.34 & $<0.05$ \\
\hline DHFR and chl. & 0.54 & $<0.05$ \\
\hline DHFR and TG. & 0.44 & $<0.05$ \\
\hline DHFR and HDL. & 0.34 & $<0.05$ \\
\hline DHFR and Creat. & -0.32 & $<0.05$ \\
\hline DHFR and $\mathrm{Na}$ & 0.34 & $<0.05$ \\
\hline DHFR and $\mathrm{K}$ & 0.1 & Non-sig. \\
\hline DHFR and ALT & 0.04 & Non-sig. \\
\hline DHFR and AST & 0.1 & Non-sig. \\
\hline
\end{tabular}

Table 3: correlation between DHFR and other biochemical parameters in female patients :

\begin{tabular}{|c|c|c|}
\hline correlation & r-value & p-value \\
\hline DHFR and FBS & 0.25 & $<0.05$ \\
\hline DHFR and ALP & 0.34 & $<0.05$ \\
\hline DHFR and urea & -0.1 & Non-sig \\
\hline DHFR and chl. & 0.4 & $<0.05$ \\
\hline DHFR and TG. & 0.41 & $<0.05$ \\
\hline DHFR and HDL. & 0.16 & Non-sig \\
\hline DHFR and Creat. & -0.005 & Non-sig \\
\hline DHFR and $\mathrm{Na}$ & 0.6 & $<0.05$ \\
\hline DHFR and $\mathrm{K}$ & 0.01 & Non-sig. \\
\hline DHFR and ALT & 0.28 & Non-sig. \\
\hline DHFR and AST & 0.35 & $<0.05$ \\
\hline
\end{tabular}

\section{Discussion:}

Now days there is a focusing on the DHFR enzyme and concept it useful genetic marker[8] and it is an excellent subject for comparative studies on the relationships between the structure and the function[14].

In this study, we have tried to address three important issues when we studied the correlation between the DHFR and some biochemical parameters in ( females \& males

First: In table-1-(Figure-1-) there is significant differences in mean values of DHFR between patients male and control male group(28.20 vs. 17.66) and there is significant difference in mean of a DHFR between patients female and control female group(28.69 vs. 21.2 ), there is no significant difference in mean values of male patients and female patients.

There are significant differences in mean value between patient (male ,female) group and control group in following biochemical parameters: FBG, urea, TG chol. HDL, creatinine, $\mathrm{Na} \& \mathrm{~K}$, while there is significant difference 
in mean value of ALP between patient group \& control group (86.76+ $\square 33.67),(86+\square 51)$ and mean value of chloride between patient group \& control group $(99.5+\square 4.15)$ vs. $(99.67+\square 3.1)$.

There are highly significant differences in mean value between patient group and control group in following biochemical parameters: ALT (24.75 $+\square 15.38),(19.13+\square 9.71$ )vs. (8.9+ $\square 0.59)$, AST (32.16+ $\square 27.02)$,

$(21.19+\square 7.7)$ vs. $(10.86+\square 0.68)$.

Second: Table (2) show depicts the correlation between the DHFR and other biochemical parameters in male patients. DHFR levels were positive significant correlated with FBG,ALP, chl. TG and positive non significant between DHFR and ALT, AST. DHFR levels were negative significant correlated with urea HDL, Creat. Na but nonsignificant with $\mathrm{K}$.

Third: Table (3) show depicts the correlation between the DHFR and other biochemical parameters in female patients . DHFR levels were positive significant correlated with FBG, ALP, Chl., TG, AST and positive non significant between DHFR and ALT. DHFR levels were negative significant correlated with Na but non- significant with urea,HDL,Creat. and K.

In conclusion: the present investigation revealed that there is relationship between the DHFR enzyme and biochemical parameters which is mention above , so we recommend to used the DHFR enzyme as the routine work for check up.

\section{References:}

[1] Mittal,J., Ravitchandirane,G., ChaudhuriT.K.,and Chaudhuri,P.(2010). Structure-activity correlationship and folding of recombinant Escherichia coli dihydro folate reductase (DHFR) enzyme through biochemical and biophysical approaches. J. Biophysical Chemistry 1(2), $105-112$.

[2] Aiso, K., Nozaki, T., Shimoda, M. and Kokue, E. (1999) Assay of dihydrofolate reductase activity by monitoring tetrahydrofolate using high-performance liquid chroma-tography with electrochemical detection. Analytical Bio-chemistry. 272(2), $143-148$.

[3] Prabhakara, K., Adinarayana, S. and Devi,R.K.(2011). Protein-Ligand interaction studies on 2, 4, 6-trisubstituted triazine derivatives as anti-malarial DHFR agents using AutoDock. Bioinformation 6(2): 74-77 .

[4] Li, M.H., Choi, S.K., Thomas, T.P. and Desai, A.(2012). Dendrimer-based multivalent methotrexates as dual acting nanoconjugates for cancer cell targeting. European Journal of Medicinal Chemistry .47:560-72.

[5] Tirakarn, S. , Riangrungroj, P. , Kongsaeree, P. and Imwong, M. (2012). Cloning and heterologous expression of Plasmodium ovale dihydrofolate reductase-thymidylate synthase gene. 61(2): 324-332.

[6] Stojković,V., Perissinotti, L. L., Willmer, D., Benkovic,S. J. and Kohen,A.(2012). Effects of the Donor-Acceptor Distance and Dynamics on Hydride Tunneling in the Dihydrofolate Reductase Catalyzed Reaction. J. Am. Chem. Soc., 134 (3), pp 1738-1745.

[7] Haurani, F. I., Kardinal, C.G.\& Biermann, W.A.(1978). Thymidylate synthetase and DHFR stimulated humanlymphocyte.J.cell Phsiol.95:49-56.

[8] Ahmed,Sh.J.(2003). Genetic \& Enzymatic study on the Mice exposed to Radiation. Ph.D. thesis. Biotechnology Department. College of Science. Baghdad University.

[9] Pagana, K.D.\& Pagana, T.J.(2006). Mosby’s Manual of Diagnostic and Laboratory Tests, 3rd ed. 8

[10] Richmond W(1973), Preparation and Properties of a Cholesterol Oxidase from Nocardia sp. and Its Application to the Enzymatic Assay of Total Cholesterol in Serum . Clinical Chemistry; 19: 1350-1356.

[11] Henary ,R.J.( 1974)Clinical chemistry ,Principles and techniques ,second edition Harper and Row :525.

[12] Patton CJ. Crouch S.R.( 1977) :Spectrophotometric and kinetics investigation of Bethelot reaction for the determination of ammonia In. : Anal Chem.;49:464-9.

[13] Doumas, B.T. and Wu, T.W(1991):The measurement of bilirubin fractions in serum .Crit.Rev.Clinic .Lab.,5-6:415-445.

[14] Zusman, T., Rosenshine, I., Beohms, G. ,Jaenicke, R., Leskiw, B. \& Mevarech, M. (1989). Dihydrofolate Reductase of the Extremely Halophilic Archaebacterium Halobacterium volcanii . J. Biol.Mol. Biol. 264(32):18878-83. 